\title{
Development of a nitrogen-doped 2D material for tribological applications in the boundary-lubrication regime
}

\author{
Shende Rashmi Chandrabhan ${ }^{1}$, Velayudhanpillai Jayan², Somendra Singh Parihar ${ }^{2}$ \\ and Sundara Ramaprabhu*1
}

\author{
Full Research Paper \\ Address: \\ ${ }^{1}$ Department of Physics, Alternative Energy and Nanotechnology \\ Laboratory, Nano Functional Materials Technology Centre, Indian \\ Institute of Technology Madras, Chennai, Tamil Nadu 600036, India \\ and ${ }^{2}$ Nano \& Applied Coating Material Laboratory, NTPC Energy \\ Technology Research Alliance (NETRA), NTPC Ltd, E3, Ecotech II, \\ Greater Noida 201306, Uttar Pradesh, India \\ Email: \\ Sundara Ramaprabhu* - ramp@iitm.ac.in \\ * Corresponding author

\section{Keywords:} \\ friction; lubrication; nanolubricant; nitrogen-doped reduced graphene \\ oxide; tribology; wear
}

\author{
Beilstein J. Nanotechnol. 2017, 8, 1476-1483. \\ doi:10.3762/bjnano.8.147 \\ Received: 14 March 2017 \\ Accepted: 27 June 2017 \\ Published: 17 July 2017 \\ This article is part of the Thematic Series "Nanotribology". \\ Guest Editor: E. Gnecco \\ (C) 2017 Chandrabhan et al.; licensee Beilstein-Institut. \\ License and terms: see end of document.
}

\begin{abstract}
The present paper describes a facile synthesis method for nitrogen-doped reduced graphene oxide (N-rGO) and the application of $\mathrm{N}-\mathrm{rGO}$ as an effective additive for improving the tribological properties of base oil. N-rGO has been characterized by different characterization techniques such as X-ray diffraction, scanning electron microscopy, transmission electron microscopy, X-ray photoelectron spectroscopy and Raman spectroscopy. N-rGO-based nanolubricants are prepared and their tribological properties are studied using a four-ball tester. The nanolubricants show excellent stability over a period of six months and a significant decrease in coefficient of friction $(25 \%)$ for small amounts of N-rGO (3 mg/L). The improvement in tribological properties can be attributed to the sliding mechanism of N-rGO accompanied by the high mechanical strength of graphene. Further, the nanolubricant is prepared at large scale (700 liter) and field trials are carried out at one NTPC thermal plant in India. The implementation of the nanolubricant in an induced draft (ID) fan results in the remarkable decrease in the power consumption.
\end{abstract}

\section{Introduction}

Advances in machine technology necessitate the reduction in energy loss by improving the tribological performance. This energy loss is caused primarily by friction and wear. The employment of lubricants in machines reduces friction and wear, which results in energy saving. However, the tribological performance of conventional lubricants (water and oil) fails to meet the demand of newly developed mechanical technologies. Recent development in lubricant technology reveals that the 
tribological performance of conventional lubricants can be improved by the addition of the solid particles [1-6]. When boundary lubrication occurs the asperities of the sliding surfaces are in direct contact with each other despite the presence of lubricant. Thus, the load is actually carried by the surface asperities [7]. The addition of solid particles is advantageous in the boundarylubrication regime since the solid particles can move to the surface-contact region and improve the lubrication. This type of lubricants makes use of the ball-bearing mechanism and the high mechanical strength of solid additives.

Several studies have been carried to investigate the tribological performance of lubricant after the addition of solid particles. Initially, most of the studies were concentrated on the carbon $\mathrm{C}_{60}$ molecules as additive in lubricant oil [8-10]. Subsequently, researchers studied the tribological properties of carbon-based additives such as graphite [1], graphene [2,6], carbon spheres $[11,12]$ and carbon nanotubes [13-15]. In addition, several reports are available on the tribological properties of nanolubricant based on metals [16], metal oxides [17,18], $\operatorname{MoS}_{2}[4,19]$, boron [20] and $\mathrm{WS}_{2}$ [21]. Among all the solid additives, 2D graphene is a promising material to improve the tribological performance because of its high surface area to volume ratio and excellent mechanical strength. Lin et al. studied the tribological properties of modified graphene platelets dispersed in oil and shows that the graphene platelets improved the wear resistance and load-carrying capacity of the machine after the modification [22]. Song et al. compared the tribological properties of multiwalled carbon nanotubes and graphene oxide nanosheets as additives for water-based lubricants and found that graphene oxide nanosheets improved the tribological properties more than the carbon nanotubes [23]. Zhang et al. studied the tribological properties of an oil lubricant with oleic acid-modified graphene and obtained $17 \%$ and $14 \%$ reduction in coefficient of friction (COF) and wear scar diameter (WSD), respectively [24]. Berman et al. studied the friction and wear characteristics of 440C steel test pairs lubricated with graphene and found a remarkable reduction in COF (from ca. 1 to ca. 0.15) and wear [25]. In addition, there are several studies carried out on reduced graphene oxide and revealed that the graphene is the most promising material for enhancing the tribological performance $[6,22,23,26-38]$. Recently, Jaiswal et al. reported the tribological study on $\mathrm{TiO}_{2}$-reinforced boron/nitrogen co-doped graphene oxide and revealed that the doping of reduced graphene oxide with heteroatoms (nitrogen, boron, co-doped nitrogen/boron) successively enhanced the antiwear properties [39]. Considering aforesaid facts, the present work describes the facile synthesis of nitrogen-doped reduced graphene oxide (N-rGO) where the surface of graphene sheet is modified by doping with nitrogen, which results in an excellent stability in base oil. Moreover, the nanolubricants prepared by dispersing a very small amount of $\mathrm{N}-\mathrm{rGO}(3 \mathrm{mg} / \mathrm{L})$ show a significant decrease in the COF (25\%) and WSD (15\%) and these are the lowest values ever reported for COF for such a small amount of N-rGO. The present work not only describes the tribological performance of the nanolubricant but also reports the application of the developed nanolubricant in an induced draft (ID) fan and thus proves the potential towards commercialization. The implementation of the prepared nanolubricants in the ID fan results a remarkable reduction in the power consumption.

\section{Experimental \\ Synthesis of N-rGO}

The synthesis of graphene oxide using Hummers method is described in Supporting Information File 1. Nitrogen-doped reduced graphene oxide (N-rGO) was prepared from melamine and GO. Melamine was used as nitrogen precursor. For this, the GO and melamine were mixed thoroughly in 1:1 ratio. The GO and melamine mixture was loaded into a tubular furnace. Initially, argon gas was flushed inside the furnace for $10 \mathrm{~min}$ to create an inert atmosphere. Afterwards, the temperature of the furnace was raised to $500{ }^{\circ} \mathrm{C}$ and hydrogen gas was flowed through for $30 \mathrm{~min}$. At this temperature, GO was exfoliated into few-layered reduced graphene oxide (r-GO). Further, the temperature of furnace was increased to $700{ }^{\circ} \mathrm{C}$. At this temperature, melamine was decomposed completely resulting in the uniform doping of nitrogen in graphene. The final sample is labeled as N-rGO. Figure 1 shows the schematic for the synthesis of N-rGO.

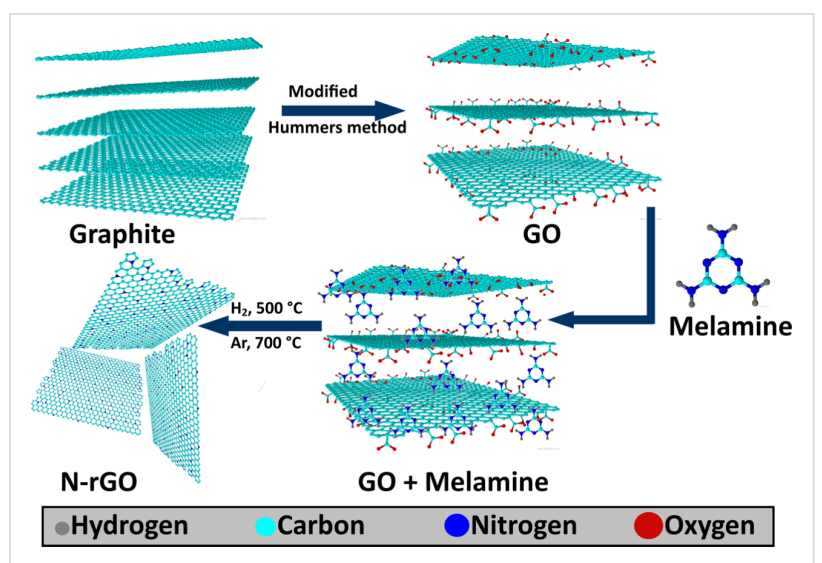

Figure 1: Schematic illustration for the synthesis of N-rGO.

\section{Characterization techniques}

The powder X-ray diffraction (XRD) patterns were recorded in the range of $2 \theta=5^{\circ}$ to $2 \theta=90^{\circ}$ using a Rigaku X-ray diffractometer. Raman scattering spectra of graphite, GO and N-rGO were collected by using a WITec Raman spectrometer equipped with Nd:YAG laser $(\lambda=532 \mathrm{~nm})$. The surface morphology of the sample was analyzed by using field-emission scanning elec- 
tron microscopy (FEI quanta FEG200). Transmission electron microscopy images were taken using transmission electron microscope (JEOL JEM-2010F) operated at $200 \mathrm{keV}$. X-ray photoelectron spectroscopy was performed to confirm the presence of various elements. Nanolubricants were prepared by using a probe sonicator (Sonics, $500 \mathrm{~W}$ ).

\section{Tribological testing}

The tribological properties of nanolubricants were studied using a four-ball tester (Magnum Engineers, Bengaluru, India). The test balls are made of chrome steel alloy having a diameter of $12.7 \mathrm{~mm}$ according to ANSI standard. The measurements were performed according to ASTM 5183 standard.

\section{Nanolubricant preparation}

Nanolubricants were prepared by dispersing N-rGO in oil using probe sonication. The probe sonication was done for $30 \mathrm{~min}$ with a $20 \mathrm{kHz}$ frequency and a power of $500 \mathrm{~W}(20 \%)$ using probe sonicator. Different nanolubricants with different amounts of N-rGO were prepared and the stability of these nanolubricants was checked by probing the settlement after onemonth time. Figure 2 shows the photographs of nanolubricants prepared in base oil with different amounts of N-rGO with a minimum of $3 \mathrm{mg} / \mathrm{L}$ and a maximum of $12.5 \mathrm{mg} / \mathrm{L}$. The N-rGO lubricants have a good stability as seen in Figure 2.

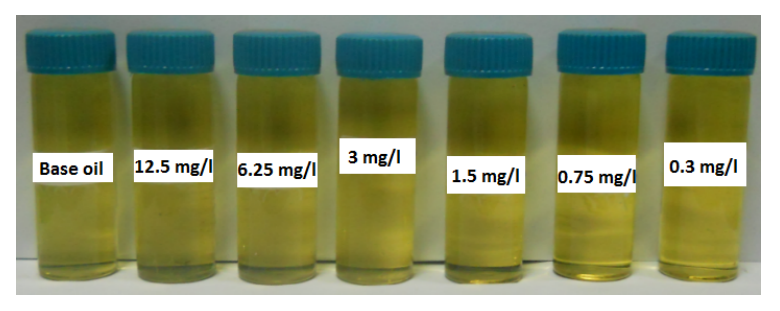

Figure 2: N-rGO dispersion nanolubricant at different concentration.

\section{Friction and wear test}

The COF and wear test of N-rGO nanolubricant was studied by using a four-ball tester. In a four-ball tribotester, an upper ball rotates with a specific speed against the three stationary balls at an applied load. This rotation results in the friction and wears at the contact points of the three stationary balls. For the present study, the friction and wear tests were carried out at a rotating speed of $600 \mathrm{rpm}$ by applying a constant load of $400 \mathrm{~N}$. The tests were carried out for $60 \mathrm{~min}$ at $75^{\circ} \mathrm{C}$. Before carrying out the measurements, the four test balls were ultrasonicated in ethanol for $10 \mathrm{~min}$ and dried. The other components were cleaned with ethanol and the cleaned three test balls were clamped together in the ball-pot assembly. The test balls were covered with nanolubricant for measurements. The fourth ball was clamped in the upper holder and the constant load of $400 \mathrm{~N}$ was applied. Figure 3 represents the schematic of the ball-pot assembly in a four-ball tester.

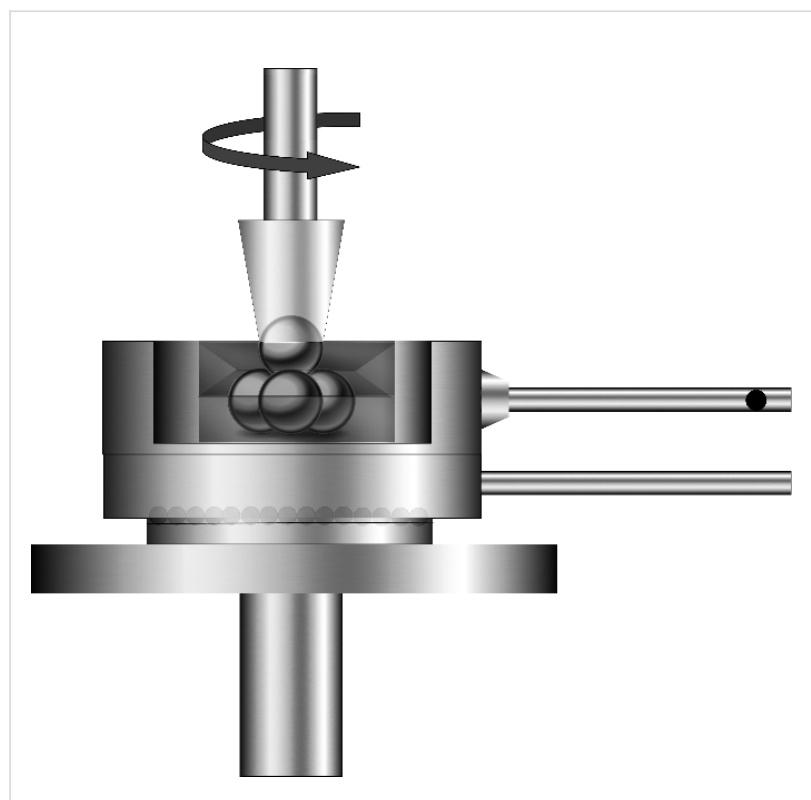

Figure 3: Schematic of the ball-pot assembly in a four-ball tester.

\section{Results and Discussion \\ Materials characterization}

The XRD patterns of graphite, GO and N-rGO are depicted in Figure S1 (Supporting Information File 1). The intense crystalline peak of graphite occurs at ca. $26^{\circ}$, which is the characteristic peak of hexagonal graphite with a $d$-spacing of $0.34 \mathrm{~nm}$. Upon conversion of graphite into GO, the peak position shifts to ca. $11^{\circ}$ corresponding to an interlayer spacing of $0.79 \mathrm{~nm}$. This increase in $d$-spacing can be attributed to the intercalation of $-\mathrm{OH}$ and $-\mathrm{COOH}$ functional groups in the graphite layers. $\mathrm{N}$-rGO shows a broad peak from ca. $15^{\circ}$ to $36^{\circ}$ with a $d$-spacing of $0.37 \mathrm{~nm}$. The decrease in the interlayer spacing from 0.79 to $0.37 \mathrm{~nm}$ suggests the removal of oxygen-containing functional groups from the GO interlayer during exfoliation [40]. This broad peak is also indicative of a loss of the long-range order in graphene.

Raman spectroscopic measurements (Figure S2, Supporting Information File 1) were performed at low laser intensities in order to avoid the burning of samples. A highly intense peak is observed for graphite at $1589 \mathrm{~cm}^{-1}$ corresponding to the $\mathrm{G}$ band. The lack of $\mathrm{D}$ band peaks in graphite implies that the graphite is defect-free. A shift of the G band of GO located at $1610 \mathrm{~cm}^{-1}$ is observed [40]. However, after reduction and nitrogen doping, the peak corresponding to the $\mathrm{G}$ band shifted back to $1589 \mathrm{~cm}^{-1}$, close to the value of graphite. The presence of the D band, with an intensity comparable to that of the 
G band, in case of GO and N-rGO suggests that defects are created during the chemical treatment.

SEM and TEM images of the N-rGO are shown in Figure S3 (Supporting Information File 1). N-rGO exhibits a wrinkled surface, which can be attributed to the rapid removal of functional groups during exfoliation. The size of N-rGO sheets is of a few square micrometers. The samples for TEM analysis are prepared by dispersing small amount of N-rGO in 2-propanol. The dispersion is ultrasonicated for $10 \mathrm{~min}$ and then drop-cast over a carbon-coated copper grid (200 mesh). TEM images shown in Figure S3c,d (Supporting Information File 1) reveal that N-rGO has few layers and shows folding at some places.

In order to confirm the nitrogen doping in N-rGO, X-ray photoelectron spectroscopy was carried out. The XPS survey spectrum of N-rGO confirms the presence of carbon (87.5 atom \%), oxygen (8.9 atom \%) and nitrogen (3.6 atom \%) (Figure S4, Supporting Information File 1). The high-resolution $\mathrm{C}$ 1s spectra show three components corresponding to $\mathrm{sp}^{2} \mathrm{C}=\mathrm{C}$ bonds (at $284.6 \mathrm{eV}$ ), $\mathrm{sp}^{2} \mathrm{C}=\mathrm{N}$ bonds (at $285.9 \mathrm{eV}$ ) and $\mathrm{sp}^{3} \mathrm{C}-\mathrm{N}$ bonds (at $288.8 \mathrm{eV}$ ). The peaks at 285.9 and $288.8 \mathrm{eV}$ can be assigned to oxygen-containing functional groups, i.e., $\mathrm{C}=\mathrm{O}$ and $\mathrm{C}-\mathrm{OH}$, respectively [41]. The high-resolution $\mathrm{N}$ 1s spectrum of N-rGO is deconvoluted into three peaks corresponding to graphitic $\mathrm{N}$ (at $401.1 \mathrm{eV}$ ), pyridinic $\mathrm{N}$ (at $398.2 \mathrm{eV}$ ) and pyrrolic $\mathrm{N}$ (at $400.1 \mathrm{eV})$.

\section{Optimization of additive}

In order to optimize the concentration of additive, the nanolubricants were prepared with various concentrations and tested their tribological properties. Figure 4 and Figure 5 give the change in the $\mathrm{COF}$ as a function of the concentration of additive (N-rGO) at the ASTM standard. One can see that the optimum amount of the additive (N-rGO) is $3 \mathrm{mg} / \mathrm{L}$ for which the maximum decrease of COF was obtained. COF decreases from 0.225 (base oil) to 0.170 ( $3 \mathrm{mg} / \mathrm{L}$ of $\mathrm{N}-\mathrm{rGO}$ ), which is a reduction of about $25 \%$. The excessive additive in base oil increases the $\mathrm{COF}$ of nano-lubricant (Figure 5). For comparison, the COF at higher concentrations of N-rGO is shown in Figure 5. The COF increases with increasing concentration of N-rGO additive. This increase can be attributed to the formation of aggregates between the contact surfaces resulting in poor lubrication. These measurements suggest that the optimum amount of additive is $3 \mathrm{mg} / \mathrm{L}$, which is the concentration used in all further experiments.

Figure 6 shows the measurements of COF with base oil and the nanolubricant with $\mathrm{N}-\mathrm{rGO}(3 \mathrm{mg} / \mathrm{L})$. The COF of nanolubricant is lower than that of base oil. For 2D nanostructures, the improvement in tribological properties is well understood as

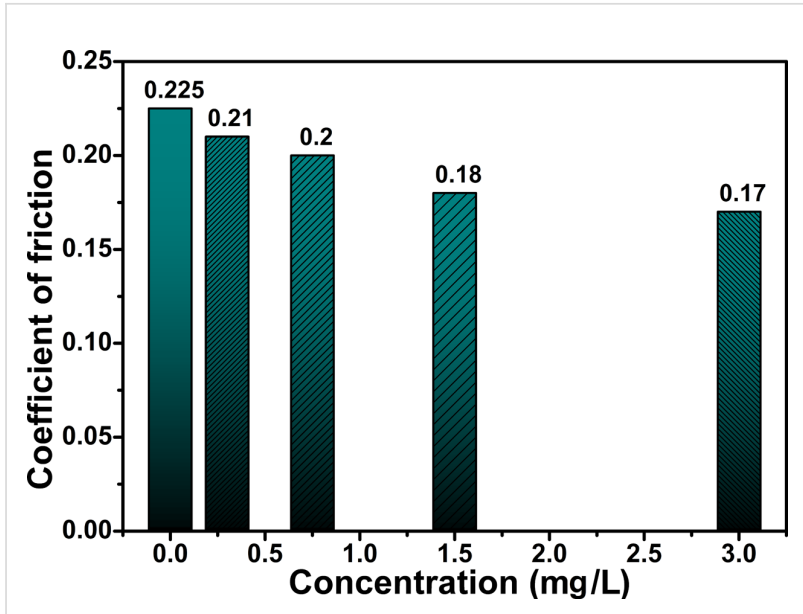

Figure 4: Coefficient of friction at low N-rGO concentrations.

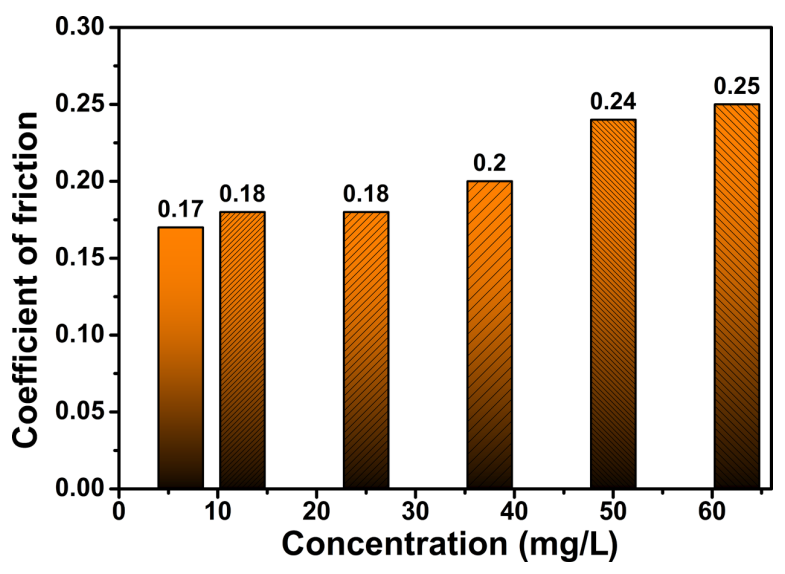

Figure 5: Coefficient of friction at high N-rGO concentrations.

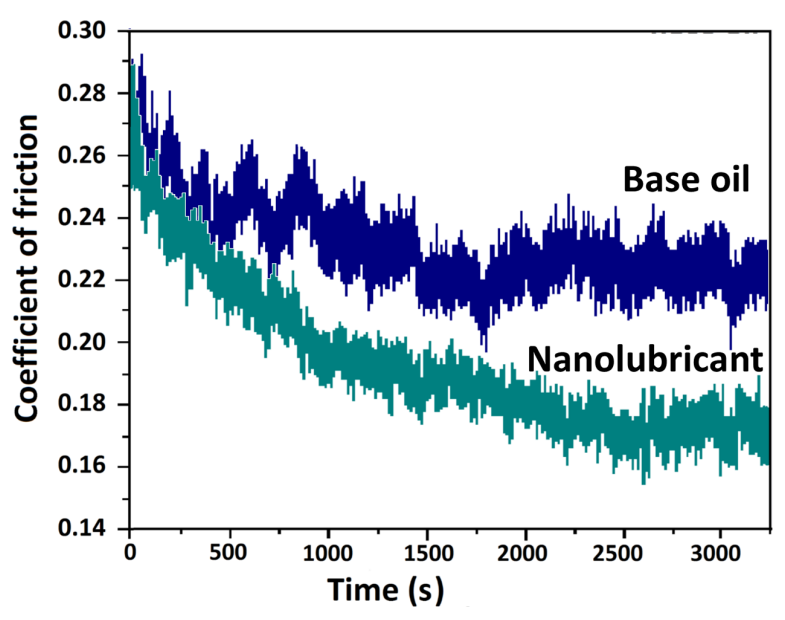

Figure 6: Variation of COF over time for base oil and nanolubricant with N-rGO (3 mg/L). 
sliding mechanism. The significant decrease in the COF for $\mathrm{N}-\mathrm{rGO}$ dispersed nanolubricant can be ascribed to the layered morphology of N-rGO, which allows the easy intrusion in the friction interfaces. In the boundary-lubrication regime, friction surfaces are in direct contact with each other and the presence of N-rGO sheets between the moving contact surfaces avoids the direct contact and thus reduces the COF.

WSD of the test ball with base oil and N-rGO nanolubricant is shown in Figure 7. With N-rGO ( $3 \mathrm{mg} / \mathrm{L})$ oil the WSD is reduced to $200 \mu \mathrm{m}$ from $230 \mu \mathrm{m}$ for base oil (15\% reduction). The significant decrease in WSD can be attributed to the easy penetration of N-rGO sheets into the contact points $[2,39]$, which reduces the direct contact between the rough surfaces.

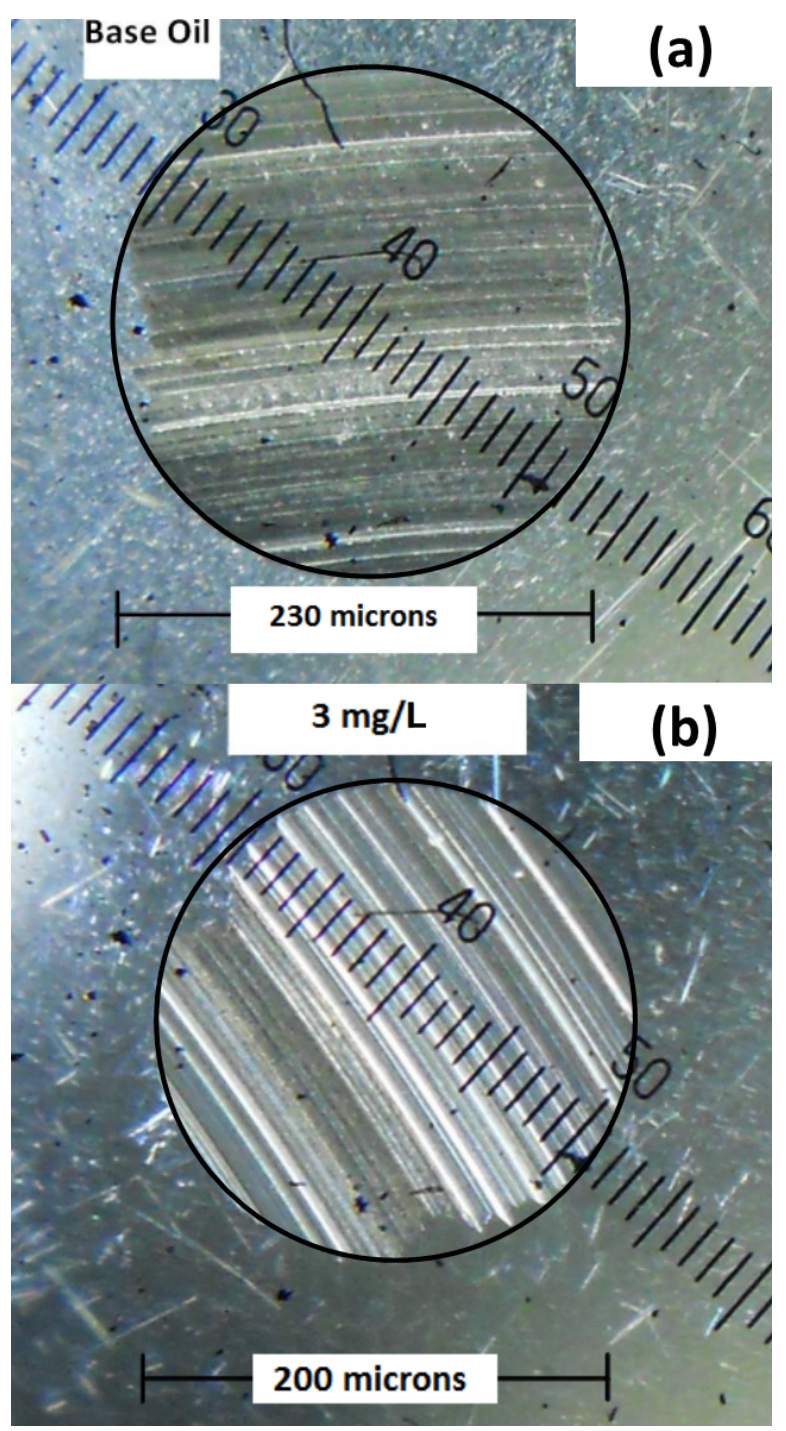

Figure 7: Wear scar diameter (WSD) of stainless steel balls lubricated with (a) base oil and (b) $\mathrm{N}$-rGO nanolubricant (3 mg/L).
The measured temperature as a function of the gradually increased normal load during the experiment is plotted and compared in Figure 8 for base oil and N-rGO oil. The temperature increased to $62.5{ }^{\circ} \mathrm{C}$ for base oil while for N-rGO nanolubricant, the temperature increased to $47.5^{\circ} \mathrm{C}$ at $1400 \mathrm{~N}$. This indicates that the developed $\mathrm{N}-\mathrm{rGO}$ based nanolubricant not only reduces the COF, but also acts as heat transfer fluid and decreases the temperature at friction interfaces.

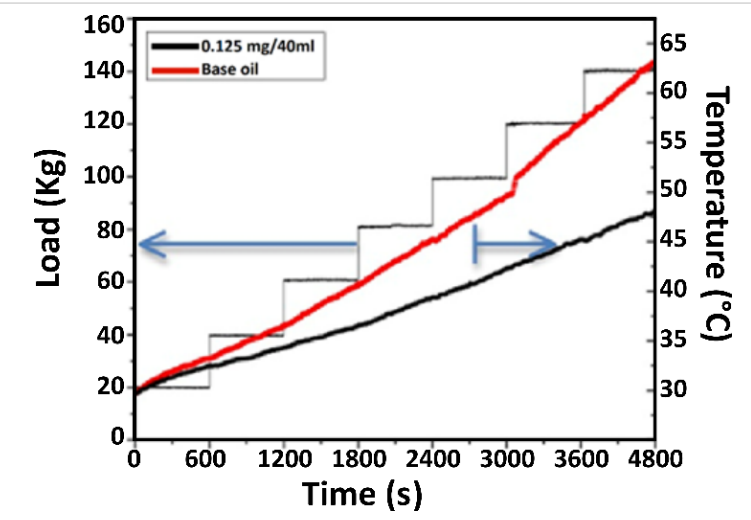

Figure 8: Comparison of the measured temperature of base oil and $\mathrm{N}-\mathrm{rGO}(3 \mathrm{mg} / \mathrm{L})$ nanolubricant as a function of the load.

\section{Application of the nanolubricant in induced draft (ID) fans}

Stable nanolubricants were prepared in large scale (700 liter) for field trial at a power plant of the National Thermal Power Corporation (NTPC) in India. The study was performed on two different induced draft (ID) fans (A and B) on two different channels (Ch 1 and $\mathrm{Ch}$ 2) using an energy management system. Initially, the data were recorded for 80 days at an interval of $1 \mathrm{~h}$ before the base oil was replaced with the nanolubricant during an overhaul. Figure $9 \mathrm{a}, \mathrm{b}$ show the variation of unit load and current in fan A and fan B for Ch 1 and Ch 2 with base oil. Figure 9a shows that the average current in Fan A and Fan B (Ch 1) is about 255 A. From Figure 9b, it is observed that the current in fan A and fan B (in Ch 2) is not exactly equal. The average value of the current of fan A turned out to be $245 \mathrm{~A}$ whereas the average value of the current of fan B was $265 \mathrm{~A}$.

The lubricant in fan A was then replaced with the N-rGO nanolubricant while the lubricant in ID fan B remained base oil in both channels. Figure 9c,d show the variation of unit load and current in Ch 1 and Ch 2 after replacing the lubricant in fan A. It is clear that the current in fan A is lower than current in fan B. For Ch 1, the average value of current for fan A and fan B was $250 \mathrm{~A}$ and $265 \mathrm{~A}$. Similarly for $\mathrm{Ch} 2$, the average value of current for fan A was $240 \mathrm{~A}$ whereas for fan B it was $275 \mathrm{~A}$. Thus, the difference in current between fan $\mathrm{A}$ and fan $\mathrm{B}$ was increased from $20 \mathrm{~A}$ to $35 \mathrm{~A}$ in $\mathrm{Ch} 2$. 

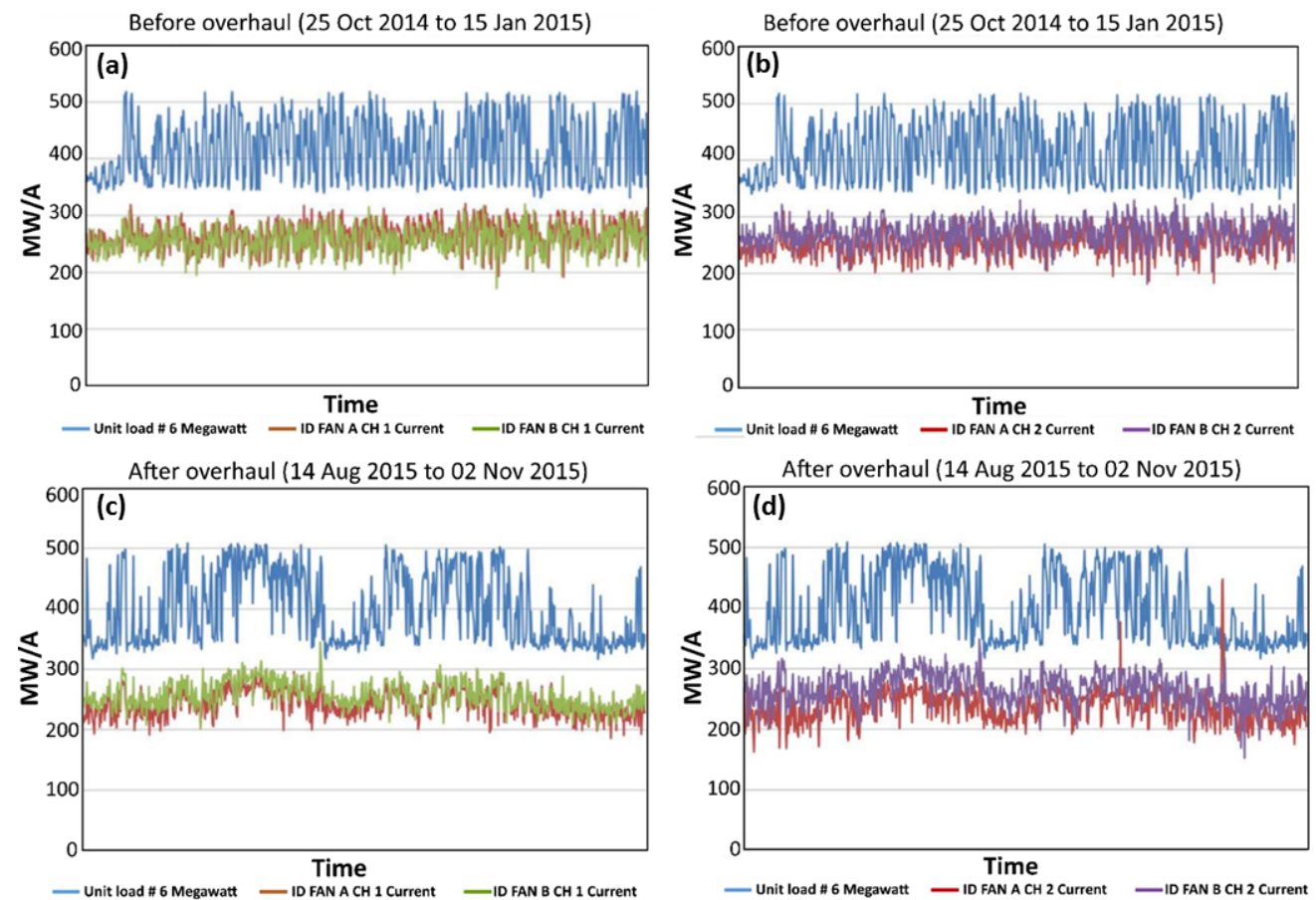

Figure 9: Unit load and current of ID fan A and B for (a) Ch 1, (b) Ch 2 before overhaul (replacement of base oil with nanolubricant), (c) Ch 1 and (d) Ch 2 after overhaul.

In summary, before the overhaul for Ch 1 there was no difference in current but after deployment of N-rGO nanolubricant the difference observed was $15 \mathrm{~A}$. In case of Ch 2, before overhaul the difference was $20 \mathrm{Amp}$, which increased to $35 \mathrm{Amp}$ after the implementation of nanolubricant. So, in conclusion the average difference due to the application of nanolubricant is $15 \mathrm{~A}$ for both channels.

Table 1 shows the power consumed by fan A and fan B for each month. It is very clear that the power consumed by fan A was considerably lower than that consumed by fan B for both channels. Figure 10 shows the total power consumption of fan $\mathrm{A}(\mathrm{Ch}$ 1 and 2) and fan B (Ch 1 and 2).

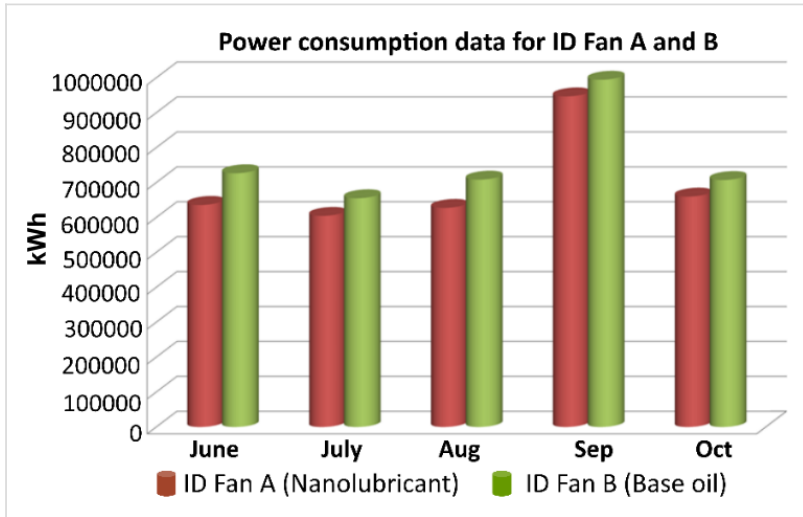

Figure 10: Power Consumption data for ID Fan A and B for few months.

Table 1: Power consumption of ID fans $A$ and $B$ over several months.

\begin{tabular}{|c|c|c|c|c|c|}
\hline & June (kWh) & July (kWh) & Aug (kWh) & Sep (kWh) & Oct (kWh) \\
\hline ID fan A (Ch 1) & 309457.92 & 294362.11 & 305819.70 & 461072.16 & 318319.49 \\
\hline ID fan A (Ch 2) & 326387.20 & 310225.23 & 321657.49 & 485770.78 & 341571.97 \\
\hline ID Fan B (Ch 1) & 366251.52 & 330099.71 & 357024.60 & 501537.57 & 356346.24 \\
\hline ID fan B (Ch 2) & 360467.45 & 324949.28 & 351382.42 & 492960.35 & 350942.59 \\
\hline ID fan $A(C h 1+C h 2)$ & 635845.12 & 604587.34 & 627477.19 & 946842.94 & 659891.46 \\
\hline ID fan B (Ch $1+$ Ch 2) & 726718.98 & 655048.99 & 708407.02 & 994497.92 & 707288.83 \\
\hline difference $(B-A)$ & 90873.856 & 50461.651 & 80929.829 & 47654.976 & 47397.376 \\
\hline
\end{tabular}




\section{Conclusion}

The present work describes the synthesis of N-rGO and a nanolubricant prepared by dispersing different amounts of nanoparticles in base oil. The study of tribological properties shows the significant decrease in COF when the nanolubricant is used. The measurement of COF was carried out for different concentrations of $\mathrm{N}-\mathrm{rGO}$ and the maximum decrease in COF (25\%) was obtained for a concentration of $3 \mathrm{mg} / \mathrm{L}$. Moreover, the WSD for nanolubricant was reduced considerably compared to the base oil. The field study of nanolubricant in ID fans shows that there is remarkable decrease in the power consumption after the application of the nanolubricant. Thus, N-rGO nanolubricants are very promising for the tribological application due to the considerable improvement of tribological properties.

\section{Supporting Information}

\section{Supporting Information File 1}

Additional experimental data.

[http://www.beilstein-journals.org/bjnano/content/ supplementary/2190-4286-8-147-S1.pdf]

\section{Acknowledgements}

This research work is supported by NTPC Ltd and authors are grateful to NTPC management for permission to publish this work. The help received from plant engineers is thankfully acknowledged.

\section{References}

1. Huang, H. D.; Tu, J. P.; Gan, L. P.; Li, C. Z. Wear 2006, 261, 140-144. doi:10.1016/j.wear.2005.09.010

2. Eswaraiah, V.; Sankaranarayanan, V.; Ramaprabhu, S. ACS Appl. Mater. Interfaces 2011, 3, 4221-4227. doi:10.1021/am200851z

3. Wu, Y. Y.; Tsui, W. C.; Liu, T. C. Wear 2007, 262, 819-825. doi:10.1016/j.wear.2006.08.021

4. Kalin, M.; Kogovšek, J.; Remškar, M. Wear 2012, 280-281, 36-45. doi:10.1016/j.wear.2012.01.011

5. Sunqing, Q.; Junxiu, D.; Guoxu, C. Wear 1999, 230, 35-38. doi:10.1016/S0043-1648(99)00084-8

6. Ota, J.; Hait, S. K.; Sastry, M. I. S.; Ramakumar, S. S. V. RSC AdV. 2015, 5, 53326-53332. doi:10.1039/c5ra06596h

7. Hamrock, B. J.; Schmid, S. R.; Jacobson, B. O. Fundamentals of Fluid Film Lubrication, 2nd ed.; Dekker: Basel, Switzerland, 2004. doi:10.1201/9780203021187

8. Grobert, N.; Terrones, M.; Osborne, A. J.; Terrones, H.; Hsu, W. K.; Trasobares, S.; Zhu, Y. Q.; Hare, J. P.; Kroto, H. W.; Walton, D. R. M. Appl. Phys. A: Mater. Sci. Process. 1998, 67, 595-598. doi:10.1007/s003390050828

9. Blau, P. J.; Haberlin, C. E. Thin Solid Films 1992, 219, 129-134. doi:10.1016/0040-6090(92)90732-Q

10. Thundat, T.; Warmack, R. J.; Ding, D.; Compton, R. N. Appl. Phys. Lett. 1993, 63, 891-893. doi:10.1063/1.109892
11. Alazemi, A. A.; Etacheri, V.; Dysart, A. D.; Stacke, L.-E.; Pol, V. G.; Sadeghi, F. ACS Appl. Mater. Interfaces 2015, 7, 5514-5521. doi:10.1021/acsami.5b00099

12. St. Dennis, J. E.; Jin, K.; John, V. T.; Pesika, N. S. ACS Appl. Mater. Interfaces 2011, 3, 2215-2218. doi:10.1021/am200581q

13. Vakili-Nezhaad, G. R.; Dorany, A. Chem. Eng. Commun. 2009, 196, 997-1007. doi:10.1080/00986440902797865

14. Yang, Y.; Grulke, E. A.; Zhang, Z. G.; Wu, G. J. Appl. Phys. 2006, 99 , 114307. doi:10.1063/1.2193161

15. Liu, L.; Fang, Z.; Gu, A.; Guo, Z. Tribol. Lett. 2011, 42, 59-65. doi:10.1007/s11249-011-9749-y

16. Tarasov, S.; Kolubaev, A.; Belyaev, S.; Lerner, M.; Tepper, F. Wear 2002, 252, 63-69. doi:10.1016/S0043-1648(01)00860-2

17. Hernández Battez, A.; González, R.; Viesca, J. L.; Fernández, J. E.; Díaz Fernández, J. M.; Machado, A.; Chou, R.; Riba, J. Wear 2008, 265, 422-428. doi:10.1016/j.wear.2007.11.013

18. Alves, S. M.; Mello, V. S.; Faria, E. A.; Camargo, A. P. P. Tribol. Int. 2016, 100, 263-271. doi:10.1016/j.triboint.2016.01.050

19. Ye, P.; Jiang, X.; Li, S.; Li, S. Wear 2002, 253, 572-575. doi:10.1016/S0043-1648(02)00042-X

20. Greco, A.; Mistry, K.; Sista, V.; Eryilmaz, O.; Erdemir, A. Wear 2011, 271, 1754-1760. doi:10.1016/j.wear.2010.11.060

21.Zhang, L. L.; Tu, J. P.; Wu, H. M.; Yang,, Y. Z. Mater. Sci. Eng., A 2007, 454-455, 487-491. doi:10.1016/j.msea.2006.11.072

22. Lin, J.; Wang, L.; Chen, G. Tribol. Lett. 2011, 41, 209-215. doi:10.1007/s11249-010-9702-5

23. Song, H.-J.; Li, N. Appl. Phys. A: Mater. Sci. Process. 2011, 105, 827-832. doi:10.1007/s00339-011-6636-1

24. Zhang, W.; Zhou, M.; Zhu, H.; Tian, Y.; Wang, K.; Wei, J.; Ji, F.; Li, X.; Li, Z.; Zhang, P. J. Phys. D: Appl. Phys. 2011, 44, 205303. doi:10.1088/0022-3727/44/20/205303

25. Berman, D.; Erdemir, A.; Sumant, A. V. Carbon 2013, 59, 167-175. doi:10.1016/j.carbon.2013.03.006

26. Song, H.-J.; Jia, X.-H.; Li, N.; Yang, X.-F.; Tang, H. J. Mater. Chem. 2012, 22, 895-902. doi:10.1039/c1jm13740a

27. Bai, G.; Wang, J.; Yang, Z.; Wang, H.; Wang, Z.; Yang, S. RSC Adv. 2014, 4, 47096-47105. doi:10.1039/C4RA09488C

28. Ye, X.; Ma, L.; Yang, Z.; Wang, J.; Wang, H.; Yang, S. ACS Appl. Mater. Interfaces 2016, 8, 7483-7488. doi:10.1021/acsami.5b10579

29. Liu, Y.; Wang, X.; Pan, G.; Luo, J. Sci. China: Technol. Sci. 2013, 56, 152-157. doi:10.1007/s11431-012-5026-Z

30. Kandanur, S. S.; Rafiee, M. A.; Yavari, F.; Schrameyer, M.; Yu, Z.-Z.; Blanchet, T. A.; Koratkar, N. Carbon 2012, 50, 3178-3183. doi:10.1016/j.carbon.2011.10.038

31. Kinoshita, H.; Nishina, Y.; Alias, A. A.; Fujii, M. Carbon 2014, 66, 720-723. doi:10.1016/j.carbon.2013.08.045

32. Llorente, J.; Román-Manso, B.; Miranzo, P.; Belmonte, M. J. Eur. Ceram. Soc. 2016, 36, 429-435. doi:10.1016/j.jeurceramsoc.2015.09.040

33. Liang, H.; Bu, Y.; Zhang, J.; Cao, Z.; Liang, A. ACS Appl. Mater. Interfaces 2013, 5, 6369-6375. doi:10.1021/am401495y

34. Tai, Z.; Chen, Y.; An, Y.; Yan, X.; Xue, Q. Tribol. Lett. 2012, 46, 55-63. doi:10.1007/s11249-012-9919-6

35. Zhang, Y.; Tang, H.; Ji, X.; Li, C.; Chen, L.; Zhang, D.; Yang, X.; Zhang, H. RSC Adv. 2013, 3, 26086-26093. doi:10.1039/c3ra42478b

36. Berman, D.; Erdemir, A.; Sumant, A. V. Carbon 2013, 54, 454-459. doi:10.1016/j.carbon.2012.11.061 
37. Huang, T.; Xin, Y.; Li, T.; Nutt, S.; Su, C.; Chen, H.; Liu, P.; Lai, Z. ACS Appl. Mater. Interfaces 2013, 5, 4878-4891.

doi:10.1021/am400635x

38. Pu, J.; Wan, S.; Zhao, W.; Mo, Y.; Zhang, X.; Wang, L.; Xue, Q.

J. Phys. Chem. C 2011, 115, 13275-13284. doi:10.1021/jp111804a

39. Jaiswal, V.; Kalyani; Umrao, S.; Rastogi, R. B.; Kumar, R.;

Srivastava, A. ACS Appl. Mater. Interfaces 2016, 8, 11698-11710. doi:10.1021/acsami.6b01876

40. Kaniyoor, A.; Baby, T. T.; Ramaprabhu, S. J. Mater. Chem. 2010, 20 , 8467-8469. doi:10.1039/c0jm01876g

41. Li, B.; Dai, F.; Xiao, Q.; Yang, L.; Shen, J.; Zhang, C.; Cai, M. Energy Environ. Sci. 2016, 9, 102-106. doi:10.1039/C5EE03149D

\section{License and Terms}

This is an Open Access article under the terms of the Creative Commons Attribution License

(http://creativecommons.org/licenses/by/4.0), which permits unrestricted use, distribution, and reproduction in any medium, provided the original work is properly cited.

The license is subject to the Beilstein Journal of

Nanotechnology terms and conditions:

(http://www.beilstein-journals.org/bjnano)

The definitive version of this article is the electronic one which can be found at: doi:10.3762/bjnano.8.147 